\title{
Práticas Interdisciplinares Apoiadas por Problemas na Formação do Técnico em Informática
}

\author{
Olavo José Luiz Junior ${ }^{1}$, Luiz Fernando Delboni Lomba ${ }^{2}$ \\ ${ }^{1}$ Instituto Federal do Paraná (IFPR) \\ ${ }^{2}$ Instituto Federal de Mato Grosso do Sul (IFMS) \\ olavo.junioreifpr.edu.br, luiz.lomba@ifms.edu.br
}

\begin{abstract}
With the implementation of the Federal Institutes, was built in Brazil an educational organization that includes courses ranging from basic education to college, providing opportunities that the concepts of computing are already introduced in basic education. Technical courses of computer area should not hold only teach the "do", but to teach "know-how" and "know seek to do."The objective of the reported activity was to increase the practical scope of application of technical disciplines course curriculum in Integrated Technical Information to high school. The approach was to develop the skills of different disciplines in a joint activity conducted from the perspective of acting in a professional environment, based on the methodology of questioning. The results show the perceptions of teachers about the evaluation process and how to operationalize activities of this nature, concluding that this approach infers more meaningful to learners, overcoming the division of labor between the actions to perform and think.
\end{abstract}

Resumo. Com a implantação dos Institutos Federais, foi construída no Brasil uma organização pedagógica que contempla cursos que vão da educação básica à superior, oportunizando que os conceitos da computação sejam introduzidos já na educação básica. Os cursos técnicos da área da computação não devem se prender apenas a ensinar o "fazer", mas o ensinar para "saber fazer" e "saber buscar o que fazer". O objetivo da atividade relatada foi ampliar o escopo de aplicação prática de disciplinas técnicas do currículo do curso Técnico em Informática Integrado ao Ensino Médio. A abordagem foi desenvolver as competências de diferentes disciplinas em uma atividade conjunta, realizada sob a ótica da atuação em um ambiente profissional, baseada na metodologia da problematização. Os resultados apresentam as percepções dos professores quanto ao processo de avaliação e quanto à operacionalização de atividades desta natureza, concluindo-se que este tipo de abordagem infere mais significado aos aprendizes, superando a divisão do trabalho entre as ações de executar e de pensar.

\section{Introdução}

O governo brasileiro propôs um modelo de proposta político-pedagógica na educação profissional, com uma organização verticalizada, que vai da educação básica ao ensino superior. É missão das escolas técnicas federais o compromisso de contribuir no desenvolvimento do país, através da criação de soluções para o desenvolvimento técnico e tec- 
nológico de cada região, de forma sustentável e buscando a inclusão social (PACHECO, 2011).

Um dos desafios que este modelo oferece é levar aos diferentes níveis de ensino conteúdos que tradicionalmente são ofertados apenas em cursos de nível superior. Assim, o objetivo deste artigo é relatar as experiências de uma proposta de intervenção realizada para o ensino de disciplinas de computação em um curso técnico de nível médio integrado em informática, utilizando-se as premissas do ensino baseado em problemas.

Na Seção 2 são apresentados conceitos que envolvem o currículo integrado e o ensino dos conteúdo de computação. A Seção 3 apresenta os trabalhos utilizados como base para esta intervenção, baseado no ensino apoiado por problemas. Na Seção 4 relatase a experiência da abordagem executada. A Seção 5 discute os resultados e a Seção 6 as conclusões do trabalho realizado.

\section{Os Conteúdos de Computação e o Ensino Médio Integrado à Educação Profissional}

O currículo da educação básica no Brasil não contempla conteúdos da área de Ciência da Computação, exceto nos cursos técnicos de nível médio do eixo tecnológico de Informação e Comunicação. Na abordagem tecnicista, ensinar os conteúdos de computação nos cursos técnicos é ensinar o uso de ferramentas para resolução de problemas do mercado. Há o equívoco de equiparar o ensino de computação ao ensino de informática, sendo este último normalmente direcionado ao ensino do uso do equipamento e das suas ferramentas. Quando se fala em ensino de computação, busca-se um nível em que as técnicas possam ser aplicadas na resolução de problemas, nas diversas áreas do conhecimento.

Nos cursos técnicos de informática há o registro de alunos que desistem por considerarem desnecessária a conclusão do mesmo, uma vez que não desejam seguir ou atuar nessa área técnica de formação. Nestes casos o objetivo do estudante é tão somente obter o título, através do aprender a "fazer", enquanto deveria contemplar o conhecimento obtido, ou seja, o "saber fazer" e "saber buscar o que fazer".

Outro aspecto a ser considerado na formação dos profissionais da computação, é a integração entre as disciplinas, valorizando o trabalho desenvolvido em cada unidade componente do currículo e mostrando a importância de cada conteúdo no contexto geral da área. Currículo é definido pelo Ministério da Educação (2007, p. 49) como "um desenho pedagógico e sua correspondente organização institucional à qual articula dinamicamente experiências, trabalho, valores, ensino, prática, teoria, comunidade, concepções e saberes observando as características históricas, econômicas e socioculturais do meio em que o processo se desenvolve".

Nesse contexto, Frigotto et al. (2005) esclarecem que o currículo integrado é aquele que tem como base a compreensão do real, colocando o currículo como a organização do conhecimento, no sentido de compreender a realidade e a própria ciência na sua historicidade. Integrar o currículo é organizar o conhecimento de maneira que os conceitos sejam compreendidos em um contexto que considere o todo. Não é apenas formar para o exercício de um ofício, mas também para a compreensão do mundo do trabalho, para uma atuação crítica e autônoma, de forma que os componentes curriculares, 
bem como os conteúdos, devem se complementar. Assim, busca-se desenvolver os fundamentos das diferentes ciências que propiciem aos jovens a capacidade analítica tanto dos processos técnicos quanto das relações sociais.

A ideia de formação integrada sugere superar o ser humano dividido historicamente pela divisão social do trabalho entre a ação de executar e a ação de pensar, dirigir ou planejar. De acordo com Frigotto et al. (2005, p. 85): "Trata-se de superar a redução da preparação para o trabalho ao seu aspecto operacional, simplificado, escoimado dos conhecimentos que estão na sua gênese científico-tecnológica e na sua apropriação histórico-social".

Conforme o Ministério da Educação (2007, p. 41) "o que se pretende é uma integração epistemológica, de conteúdos, de metodologias e de práticas educativas. Refere-se a uma integração entre teoria e prática, entre o saber e o saber-fazer". Em complemento, não se deve descartar as demandas oriundas do mercado de trabalho, que é dinâmico. A formação integrada deve apresentar elementos que contextualizem a realidade a ser vivenciada no exercício profissional.

Segundo Pacheco (2011, p. 15), a proposta pedagógica da educação profissional deve recusar o conhecimento exclusivamente voltado a formação da mão de obra e deve valorizar a relação do homem com o mundo: "Sua orientação pedagógica deve recusar o conhecimento exclusivamente enciclopédico, assentando-se no pensamento analítico, buscando uma formação profissional mais abrangente e flexível, com menos ênfase na formação para ofícios e mais na compreensão do mundo do trabalho e em uma participação qualitativamente superior nele".

A escola técnica onde se ambienta esse artigo foi inaugurada no ano de 2010 . O início de suas atividades não trouxe novidades apenas à comunidade local, mas também aos profissionais que assumiam os cargos de professores nos primeiros cursos ofertados pela instituição, considerando a estrutura de formação verticalizada que permite ao docente atuar em diferentes níveis de ensino, que podem ir do nível médio ao doutorado. Em geral, os docentes vinham de experiências apenas com docência na graduação em cursos de engenharias e de computação, sem experiências no ensino técnico de nível médio.

Os autores iniciaram suas atividades no curso técnico de nível médio integrado em informática com o desafio de lecionar em um nível de ensino em que nunca haviam atuado. Para superar o paradigma da fragmentação, segundo Ferreira et al. (2010, p. 52), é necessário que o docente tenha "uma visão sistêmica, atuando de maneira significativa, onde seu papel de pesquisador e mediador seja evidente e colabore para o desenvolvimento de um ser integral e pleno". Os autores procuraram pautar sua atuação nessa premissa.

Os autores consideram a avaliação como um evento importante para a aprendizagem, sobretudo na educação profissional. Como diz Moretto (2010, p. 18), a avaliação é um momento privilegiado de estudo, no qual "o ensino proporciona o desenvolvimento de habilidades e a aquisição de conhecimentos, que conduzem às competências almejadas".

A atividade prática interdisciplinar oportuniza ao estudante um feedback imediato sobre seu real aprendizado, bem como, de acordo com a condução da atividade, permite a reflexão sobre a melhor alternativa para resolução dos problemas, ajudando na aprendizagem significativa. 


\section{O Ensino Apoiado por Problemas}

Com o objetivo de quebrar a abordagem tradicional das aulas, centrada no professor como transmissor dos conteúdos, buscou-se uma metodologia que coloque o aluno como o centro do processo de ensino-aprendizagem. Segundo Almeida e Moran (2005, p. 64) "na perspectiva da interatividade, o professor pode deixar de ser um transmissor de saberes para converter-se em formulador de problemas, provocador de interrogações, coordenador de equipes de trabalho, sistematizador de experiências e memória viva de uma educação que, em lugar de prender-se à transmissão, valoriza e possibilita o diálogo e a colaboração". Sob esta óptica adotou-se uma metodologia baseada em problemas para realizar algumas das atividades de um curso técnico em informática.

A Metodologia da Problematização, proposta por Charlez Maguerez (BORDENAVE e PEREIRA, 1982 apud BERBEL, 1995) e baseada no "Método do Arco", utilizase dos problemas como base para o processo de ensino-aprendizagem, em um circuito de etapas: observação da realidade, para identificar o problema; definição de pontos-chave, elencando os tópicos a serem investigados; teorização, para construir respostas concretas para o problema; hipóteses de solução, para alinhar os conceitos teóricos à realidade; e por fim, a aplicação prática, em que efetivamente há a intervenção sobre o problema. Segundo Berbel (1995) ela apoia-se na realidade do contexto, que observada sob diversos ângulos "manifesta-se para alunos e professor, através dos fatos concretos e daí são extraídos os problemas."

Outra abordagem é o Método de Aprendizagem Baseada em Problemas (Problem Based Learning - PBL), que de acordo com Sakai e Lima (1996 apud BERBEL, 1998) "é o eixo principal do aprendizado teórico do currículo de algumas escolas de Medicina, cuja filosofia pedagógica é o aprendizado centrado no aluno". O PBL é uma "metodologia formativa à medida que estimula uma atitude ativa do aluno em busca do conhecimento e não meramente informativa como é o caso da prática pedagógica tradicional."

Apesar da semelhança entre as duas metodologias há diferenças na concepção e na execução delas. Dentre as diferenças, apontadas por Berbel (1998), destaca-se o fato de que a Metodologia da Problematização não requer grandes alterações materiais ou físicas na escola: "as mudanças são mais na programação da disciplina", enquanto na PBL há necessidade de adequações nos espaços físicos (que devem ser suficientemente equipados e espaçosos), da equipe de trabalho, da organização dos horários, na distribuição de temas versus tempo, entre outras.

Os trabalhos na literatura sobre a abordagem apoiada por problemas na área de computação, em geral, apontam para o uso do PBL. O trabalho de Araújo et al. (2015) relata a experiência de um minicurso realizado por estudantes do curso de Licenciatura em Computação, utilizando a abordagem por problemas para ensinar lógica de programação aos alunos do ensino fundamental, a partir do uso de atividades da computação desplugada $^{1}$ e do software scratch $^{2}$.

\footnotetext{
${ }^{1}$ A Computação Desplugada (Computer Science Unplugged) é um método que defende o ensino de computação sem o uso do computador e permite que o aluno use o pensamento computacional para resolver problemas reais.

${ }^{2}$ Scratch é uma plataforma de programação, com uma sintaxe simples, comumente utilizada para introduzir à programação quem não tem experiência no assunto.
} 
Nos cursos de computação as disciplinas de algoritmos e programação, em geral, são classificadas pelos alunos como difíceis, justamente pela natureza voltada à resolução de problemas. Espelhado na experiência de Araújo et al. (2015), entende-se que utilizar esta abordagem em outras áreas do curso é uma oportunidade de retirar destas disciplinas a responsabilidade exclusiva de levar o aluno a raciocinar, já que "a computação, enquanto ciência tem como objeto de estudo a resolução de problemas". Temos no bojo dos cursos técnicos a oportunidade de introduzir os conceitos da Ciência da Computação já na educação básica, disseminando o pensamento computacional.

Outra experiência é apresentada por Notari et al. (2009), que utilizou a Aprendizagem Baseada em Problemas, em uma disciplina do curso de Licenciatura em Computação. O objetivo era ensinar o processo de instalação e configuração de Sistemas Operacionais, com enfoque na aprendizagem colaborativa, despertando a capacidade dos alunos em "trabalhar em conjunto para identificar e analisar problemas e/ou gerar soluções".

O trabalho de Oliveira et al. (2007) apresenta a experiência de um curso de Engenharia da Computação com o PBL, destacando o trabalho desenvolvido na disciplina de Arquitetura de Computadores. Adaptando Venturelli (1997), os autores apontam três adaptações para a aplicação da metodologia em cursos diferente da Medicina e que se encaixam no contexto de um curso de ensino médio integrado: integrar as disciplinas em eixos temáticos; desenvolver estudos baseados em problemas e fundamentados na realidade; e utilizar um mecanismo de avaliação diferenciada, que seja contextualizada e permita uma reflexão do aluno sobre sua prática.

Segundo Berbel (1998), a PBL impacta na reorganização curricular do curso, enquanto a Metodologia da Problematização "pode ser utilizada para o ensino de determinados temas de uma disciplina". Assim, o presente trabalho se deu baseado Metodologia da Problematização, mas apoiado na experiência de Oliveira et al. (2007), a fim de aplicar as adaptações sugeridas do PBL para introduzir uma nova concepção no contexto do curso técnico em informática, sem a necessidade de grandes mudanças na estrutura do curso e da escola.

\section{Relato e Metodologia da Intervenção}

A primeira etapa foi identificar e relacionar as disciplinas que se encaixam no eixo temático definido como Manutenção de Computadores, considerando a estrutura curricular do curso técnico de nível médio integrado em Informática em que esta experiência foi realizada. Quatro disciplinas foram agrupadas neste eixo e são apresentadas na Figura 1, que também apresenta em qual semestre do curso cada uma delas é oferecida.

Em um segundo passo foi elaborado um plano de ação para o eixo temático, para garantir que os conteúdos de uma disciplina pudessem complementar o de outra e de que não haveria sobreposição entre eles. A Tabela 1 mostra a ementa das disciplinas que compõem o eixo.

A disciplina de Organização de Computadores é a responsável por introduzir os conceitos fundamentais do sistema computacional, com ênfase nos componentes que compõem um computador de mesa (desktop) e os seus detalhes técnicos. Diferente da abordagem tradicionalmente abordada nesta disciplina, aqui o foco é apresentar o contexto prático de como o técnico em informática utilizará estes conceitos. Por exemplo, 


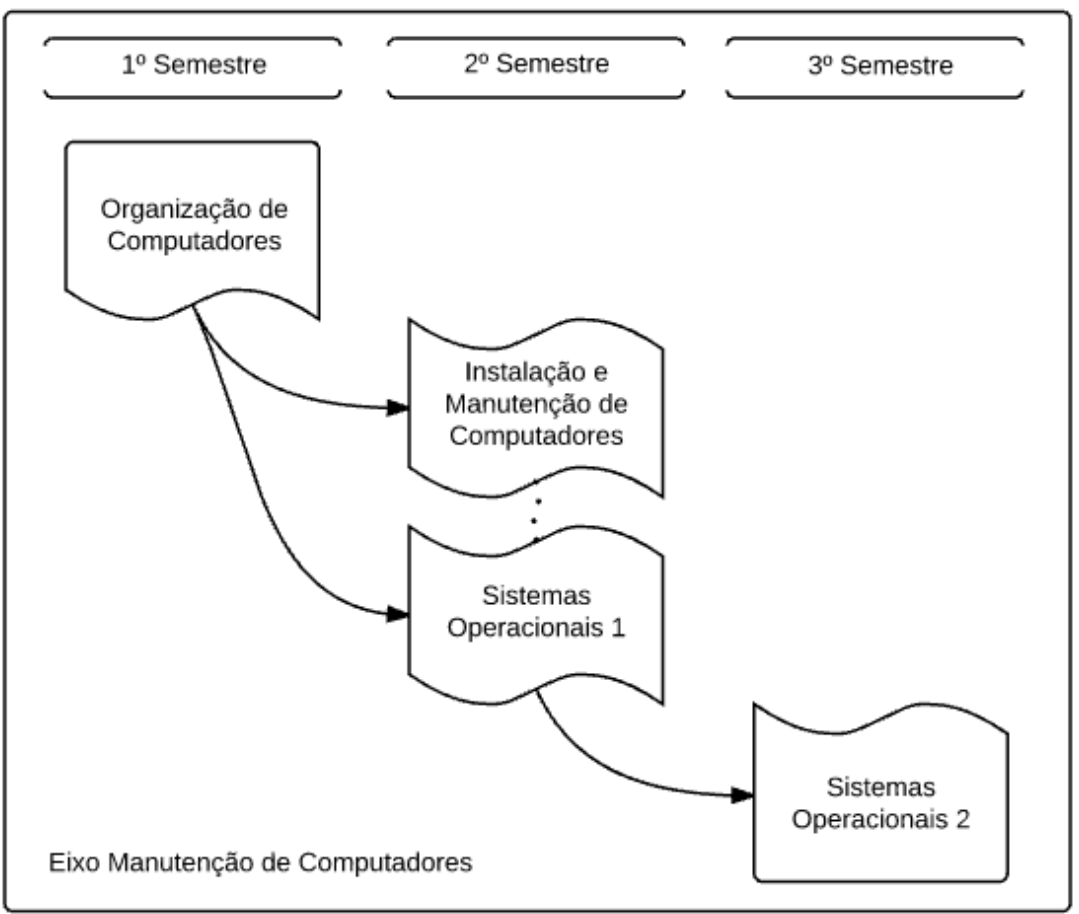

Figura 1. Organização das discipinas no Eixo Manutenção de Computadores

na apresentação da hierarquia de memórias, o foco é permitir que o aluno identifique as características delas nos componentes do computador: nos conceitos de memória cache, por exemplo, o aluno deve identificar que se trata de um detalhe técnico do processador e que através dos manuais dos processadores é possível identificar esta característica.

Nas disciplinas de Instalação e Manutenção de Computadores e Sistemas Operacionais 1 , o objetivo é permitir que o estudante faça a instalação e configuração de um computador: configuração da BIOS, instalação do sistema operacional, aplicativos e drivers, identificação de falhas físicas e de software (troubleshooting).

Já na disciplina de Sistemas Operacionais 2 são abordados os temas mais clássicos da disciplina, porém com o foco em mostrar a aplicação de cada um delas, através do uso de utilitários disponíveis nos sistemas proprietários e livres do mercado.

Tabela 1. Ementa das disciplinas do Eixo Manutenção de Computadores.

\begin{tabular}{|c|c|}
\hline \multicolumn{2}{|c|}{ Eixo: Manutenção de Computadores } \\
\hline Disciplina & Ementa \\
\hline $\begin{array}{c}\text { Organização de } \\
\text { Computadores }\end{array}$ & $\begin{array}{c}\text { Estrutura básica e conceitos fundamentais da informática. Tipos de } \\
\text { componentes e periféricos. Critérios para seleção de hardware. }\end{array}$ \\
\hline $\begin{array}{c}\text { Configuração e instalação de microcomputadores e seus periféricos. } \\
\text { Tnstalação e } \\
\text { Manutenção } \\
\text { de Computadores de Manutenção Preventiva e Corretiva. Realização de cópias de } \\
\text { segurança, restauração de dados e atividades de prevenção, detecção e } \\
\text { remoção de vírus. Seleção de soluções adequadas para corrigir as falhas } \\
\text { de funcionamento de computadores, periféricos e softwares. }\end{array}$ \\
$\begin{array}{c}\text { Evolução histórica dos Sistemas Operacionais. Arquiteturas computacionais } \\
\text { e os Sistemas Operacionais. Tipos de Sistemas Operacionais. Instalação e } \\
\text { configuração de Sistemas Operacionais. Utilização de programas utilitários } \\
\text { Operacionais 1 modo texto e modo gráfico. }\end{array}$ \\
\hline $\begin{array}{c}\text { Sistemas } \\
\text { Operacionais 2 }\end{array}$ & $\begin{array}{c}\text { Processamento. Processos, Sincronização, comunicação inter-processos. } \\
\text { Gerenciamento de CPU, Memória e Entrada/Saída. Sistemas de Arquivos. }\end{array}$ \\
\hline
\end{tabular}


A etapa seguinte foi planejar as atividades a serem realizadas em cada uma das unidades curriculares, baseado em problemas. Apesar das unidades curriculares serem ministradas por docentes diversos e em dias diferentes, o plano de ação permitiu a identificação de problemas que poderiam ser abordados em conjunto, cabendo ao professor relacionar os conteúdos com os das outras disciplinas. Assim, as disciplinas de Instalação e Manutenção de Computadores e Sistemas Operacionais 1, ofertadas simultaneamente no $2^{\circ}$ semestre do curso, foram planejadas para que ocorressem de forma integrada.

Posto esta organização, relata-se a seguir a realização de uma avaliação prática conjunta entre os dois componentes curriculares. Além de integrar os conceitos abordados das disciplinas, procurou-se avaliar as competências de ambas através de um problema conjunto, contextualizando o problema em um cenário do mercado, que simulava o ambiente de uma empresa prestadora de serviços.

O problema proposto exigia que o aluno aplicasse técnicas de manutenção corretiva (para solucionar os problemas de funcionamento do computador), manutenção preventiva (para otimizar/personalizar as configurações do computador) e de instalação de softwares (sistema operacional, aplicativos e drivers).

Cada aluno recebeu um modelo simulado de contrato e ordem de serviços (Figura 2) com uma série de trabalhos a serem efetuados em um computador, sendo estes complementares e interdependentes. O laboratório foi preparado pelos professores de forma a gerar problemas técnicos no funcionamento dos computadores a serem utilizados na atividade.

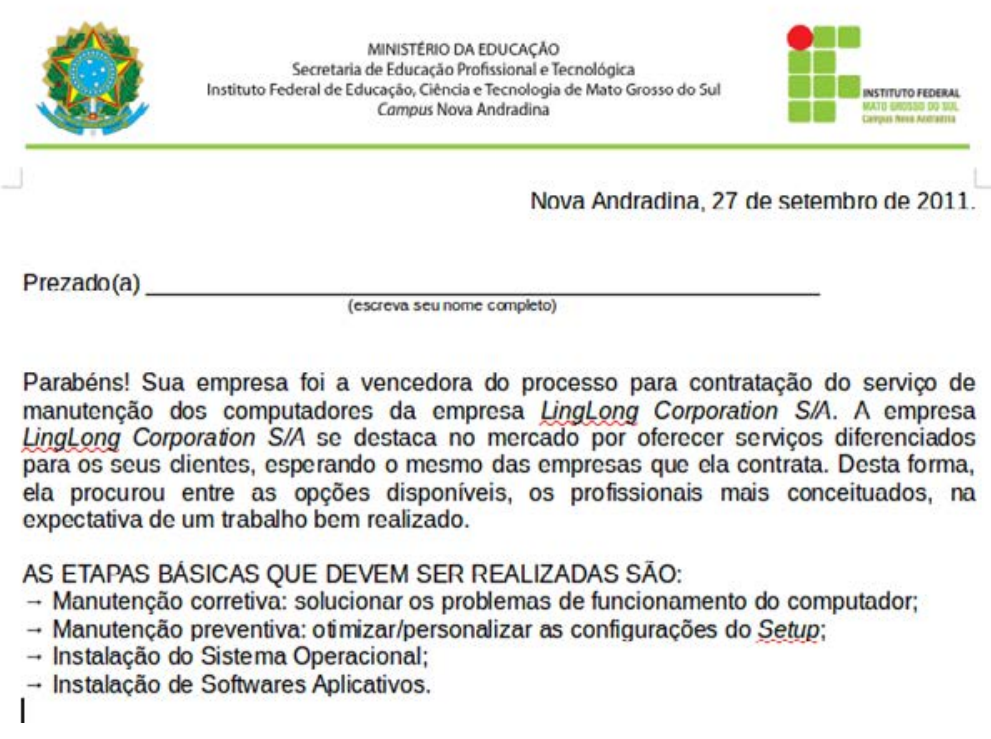

Figura 2. Fragmento do simulacro utilizado na atividade

Além da realização e finalização correta das tarefas técnicas propostas, a atividade deveria ser finalizada com o preenchimento de relatório técnico que procedesse prestação de contas ao cliente do que foi efetivamente realizado e qual a razão de cada intervenção técnica. Com o intuito de considerar outros aspectos da formação integral do indivíduo e do profissional, foram introduzidos parâmetros como compromisso e profissionalismo na atividade. 
Outro objetivo focava em que o estudante pudesse mensurar o resultado financeiro do seu trabalho, além de identificar a importância de informar às pessoas que confiaram em seu trabalho, o que e o porquê do serviço que foi realizado, de forma transparente e adequada. O enunciado do exercício sugeria: "Lembrando que conforme combinado na proposta do contrato, o serviço será 'pago' somente após a apresentação do relatório dos serviços prestados e a conclusão dos mesmos”, de forma a traçar um paralelo entre o pagamento do serviço na vida real, com a atribuição do conceito escolar referente à atividade.

Após a realização da primeira parte da avaliação, que os alunos consideravam que era única e estaria finalizada, os professores aplicaram um novo desafio, exigindo que novas instalações/configurações fossem realizadas, fazendo um paralelo com solicitações de serviço de pós-venda muitas vezes existentes em ocorrências reais da vida profissional. Essa situação levaria à uma necessária reflexão sobre as consequências de sua intervenção técnica no médio prazo, procurando sempre executar da melhor forma as instalações solicitadas.

\section{Resultados e Discussões}

Quando a atividade foi revelada aos estudantes, a reação dos mesmos foi apresentar a preocupação que um possível mau desempenho na avaliação resultaria em uma "nota ruim" nas duas disciplinas. Alguns alunos questionaram se a nota seria zero caso não conseguissem finalizar a atividade, Muitos também perguntaram se a prova de recuperação seria feita em um formato similar, demonstrando contrariedade, o que evidencia a cultura ainda existente entre os estudantes de que o que esperam em uma avaliação é a nota à ela atribuída e não o processo e a aprendizagem que a envolve. Mesmo assim, ao final da atividade a percepção dos alunos foi considerá-la uma avaliação mais interessante do que o usual, haja vista que os motiva a utilizar conteúdos de componentes curriculares diversos.

Quanto aos professores, verificou-se que o formato das atividades permitiu uma maior facilidade por parte dos estudantes em demonstrar de fato a aprendizagem e isso se refletiu naturalmente em uma melhoria no resultado, em comparação com avaliações realizadas anteriormente.

Para realizar esta atividade, foram necessárias algumas alterações na organização e logística das aulas. Para este dia, excepcionalmente, as aulas das duas disciplinas foram agrupadas, a fim de permitir tempo suficiente para o estudante identificar os problemas, solucioná-los e para que escrevesse o relatório. Esta situação exigiu que outros professores colaborassem, cedendo o tempo de suas aulas. Este aspecto mostra a necessidade dos professores refletirem sobre sua prática e mudarem as características habituais de preparação das aulas, que tendem a uma rotina de repetição e reprodução (mais do mesmo...).

Em geral, o professor até quer integrar a sua disciplina, mas não quer modificar sua forma de atuar, esperando que a outra área de conhecimento se integre à sua. Uma atividade integrada exige que o professor saia de sua área de atuação e passe a encontrar pontos convergentes em outras áreas do conhecimento. A partir da abordagem por problemas, foi possível criar um ponto $\mathrm{C}$, que agregou as áreas $\mathrm{A}$ e $\mathrm{B}$, não apenas somando os conteúdos, mas criando um novo ponto a partir da convergência deles. 
Esta experiência envolveu professores que ministram disciplinas diferentes mas atuam em área comum, o que acabou facilitando a execução da experiência. Destarte, a organização do eixo de Manutenção de Computadores possibilitou que todos os professores envolvidos tivessem uma visão macro da área, indo além da sua unidade curricular. É provável que a agregação de conteúdos de outras áreas do conhecimento (através do trabalho dos respectivos docentes) ampliasse fortemente a necessidade de planejamento e preparação mais sofisticados da atividade, bem como demandasse um acompanhamento mais apurado dos resultados.

\section{Conclusões}

Os professores perceberam que o argumento utilizado, que coloca o aluno no papel de um profissional perante um problema, mostrou ser um formato que representou mais significado aos aprendizes sobre os conteúdos trabalhados. Com a problematização foi possível simular um ambiente mais próximo do encontrado na vida profissional, exigindo que os alunos identificassem os problemas e teorizassem hipóteses de acordo com o conhecimento obtido nas disciplinas, e aplicassem à realidade.

Esta experiência ficou restrita à integração das disciplinas de apenas uma área, sendo que novas experiências deverão ser realizadas para atingir as outras áreas do conhecimento, que envolvem a formação do aluno para uma atuação crítica e autônoma.

Quanto à metodologia utilizada, conclui-se que é necessário quebrar a abordagem tradicional utilizada, que está centrada no conteúdo e avaliada de acordo com a nota obtida na prova. O aluno precisa ser agente ativo do processo e não mero consumidor do conteúdo.

Aplicar este tipo de abordagem em momentos pontuais pode deixar o aluno desorientado. Faz-se necessário que esteja presente em outros momentos e não pontualmente em uma ou outra atividade, para que o aluno se aproprie da mesma e passe a ser o agente principal do processo. Iniciar o trabalho com um grupo de disciplinas é uma oportunidade para buscar a desmistificação do trabalho interdisciplinar, apresentando-se gradativamente como alternativa factível e viável entre todos os docentes.

Esta abordagem mostrou-se como uma oportunidade para superar a divisão do trabalho entre as ações de executar e de pensar, a partir de um problema conjunto, próximo à realidade que será encontrada pelo estudante em sua atuação profissional. Colocar o aluno como agente ativo e crítico do processo, proporcionará a sua aproximação do mundo real, sobrepondo o papel de mero executor de tarefas.

\section{Referências}

Almeida, M. E. B. and Moran, J. M. (2005). Integração das Tecnologias na Educação. Ministério da Educação, Seed, Brasília, DF.

Araújo, D. C., Rodrigues, A. N., Silva, C. V. A., and Soares, L. S. (2015). O ensino de computação na educação básica apoiado por problemas: Práticas de licenciandos em computação. In XXIII Workshop sobre Educação em Informática - Anais do XXXV Congresso da Sociedade Brasileira de Computação, Recife. SBC.

Berbel, N. A. N. (1995). Metodologia da problematização: uma alternativa metodológica apropriada para o ensino superior. Semina: Ciências Sociais e Humanas, 16(2):9-19. 
Berbel, N. A. N. (1998). A problematização e a aprendizagem baseada em problemas: diferentes termos ou diferentes caminhos? Interface - Comunicação, Saúde, Educação, 2(2):139-154.

Bordenave, J. D. and Pereira, A. M. (1982). Estratégias de ensino aprendizagem. Vozes, Petrópolis.

Ferreira, J. L., Carpim, L., and Behrens, M. A. (2010). Do paradigma tradicional ao paradigma da complexidade: um novo caminhar na educação profissional. Boletim Técnico do Senac: a Revista da Educação Profissional, 36(1):51-59.

Frigotto, G., Ciavatta, M., and Ramos, M. (2005). Ensino médio integrado: concepção e contradições. Cortez, São Paulo.

Ministério da Educação (2007). Programa Nacional de Integração da Educação Profissional com a Educação Básica na Modalidade de Educação de Jovens e Adultos. Ministério da Educação, Brasília.

Moretto, V. P. (2010). Prova: Um Momento Privilegiado de Estudo, Não Um Acerto de Contas. 9 ed. Lamparina, Rio de Janeiro.

Notari, D. L., Bohn, J., and Boff, E. (2009). Uma abordagem baseada em problemas para aprendizagem colaborativa de sistemas operacionais. In XVII Workshop sobre Educação em Informática - Anais do XXIX Congresso da Sociedade Brasileira de Computação, Bento Gonçalves. SBC.

Oliveira, W. L. A., Arruda, G. H. M., and Bittencourt, R. A. (2007). Uso do método pbl no ensino de arquitetura de computadores. In Proceedings of the 2007 International Conference on Engineering and Computer Education, Santos. International Conference On Engineering and Computer Education.

Pacheco, E. (2011). Institutos Federais: uma revolução na educação profissional e tecnológica. Moderna, Brasília.

Sakai, M. H. and Lima, G. Z. (1996). Pbl: uma visão geral do método. Olho Mágico, 2(5/6):51-59.

Venturelli, J. (1997). Educación médica. Serie PALTEX salud y sociedad 2000. Organización Panamericana de la Salud, Washington. 